\title{
Do it yourself cardioversion
}

\section{J A McKnight, K Balnave, D B O'Keeffe}

\begin{abstract}
Sir George E Clark
Metabolic Unit, Royal

Victoria Hospital, Belfast

BT12 6BA, Northern

Ireland

J A McKnight, MRCP,

registrar
\end{abstract}

Craigavon Area Hospital, Craigavon, County Armagh BT63 5QQ, Northern

Ireland

K Balnave, MRCP, consultant physician

\section{Belfast City Hospital,} Belfast BT9 7AB

D B O'Keeffe, MRCP, consultant physician

Correspondence to: Dr McKnight.
Medical history taking sometimes elicits unusual and interesting stories. Patients' perceptions and managements of their problems before they seek medical attention can produce some surprises. Unusual remedies that work may later be explained by accepted medical logic. This is certainly true of the case reported here.

\section{Case report}

A 62 vear old farmer first came to medical attention at Craigavon Area Hospital in 1982. The cardiac ambulance had been asked to attend him as he had become unconscious in his front garden. Electrocardiography confirmed a supraventricular tachycardia. He was hypotensive and was admitted for further investigation. During the next few days his interesting history emerged.

He had first noticed palpitations in 1954. During a typical attack he would notice his heart racing and would feel dizzy. He would not be short of breath. Initially the attacks did not last long. During the next few years their duration increased to about 10 hours. He thought that they were precipitated by excitement, trauma to his chest, or a shock and decided that a shock or trauma would also stop them.

Initial treatment consisted of his jumping off a barrel in his farmyard and thumping his feet hard on the ground when landing. This worked well for a few years. If this failed he used to climb a ladder because this was higher, and jump. Alternative treatment was to fire a 12 bore shotgun as he found that this might stop his palpitation.

Second line treatment was a little more invasive. He had a cold water tank on the farm. He was able to stop his palpitation by taking off his clothes and jumping in. As a cattle farmer third line treatment was obvious: grasping his six volt electric cattle fence was very effective. It worked best if he was wearing his hobnailed boots. If he was wearing rubber boots the shock was administered by grasping the fence in one hand and sticking a finger of the other hand into the ground.

The medical profession had difficulty managing his palpitations. During 1982-4 he received a wide range of drugs, but these either failed to control his symptoms or caused side effects. He required admission for treatment on eight occasions. Outpatient notes stated that a Valsalva manoeuvre or squatting relieved symptoms.

He was referred to Belfast City Hospital for electrophysiological studies. The final diagnosis was of a reciprocating junctional tachycardia with retrograde conduction along a septal or paranodal accessory pathway. This was treated with a right ventricular pacemaker (Telectronics PASAR 4172) that recognised ventricular rates of greater than 155 beats/minute and emitted two right ventricular stimuli. Subsequently he was admitted on only one occasion for treatment of palpitations.

\section{Comment}

Short episodes of junctional tachycardia without distress do not require treatment. Standard treatment in more severe cases is to increase vagal tone. ${ }^{\prime}$ Methods used include carotid sinus massage, the Valsalva manoeuvre, the diving reflex, and eyeball pressure. If these treatments fail intravenous verapamil is the best treatment if there are no contraindications. If clinical circumstances dictate immediate restoration of a slower rhythm the treatment is synchronised direct current cardioversion.

A Valsalva manoeuvre is probably the mechanism by which our patient initially reverted his rhythm when jumping from a height or firing a shotgun. He brought his electric fence to the hospital and used it to stop a tachycardia. Electrocardiography showed that the fast rhythm persisted for three beats after the shock, implying that the mechanism of action was probably stimulation of the vagus. Our patient's use of the diving reflex and his do it yourself "electric cardioversion" are, however, a little extreme for standard medical teaching.

1 Metha D, Ward DE, Wafa S, Camm AJ. Relative efficacy of various physica mano uvres in the termination of junctional tachycardia. Lancet 1988; $1181-5$.

\section{Periareolar pilonidal abscesses in a hairdresser}

\author{
M X Gannon, M C Crowson, J W L Fielding
}

\begin{abstract}
Department of Surgery, Queen Elizabeth Hospital, Birmingham B15 2TH M X Gannon, FRCS, registrar in surgery

M C Crowson, FRCS, senior registrar in surgery

$\mathrm{J}$ W L Fielding, FRCS, consultant surgeon
\end{abstract}

Correspondence to: $\mathrm{Mr}$ Gannon.
Periareolar inflammation and abscesses can be difficult clinical problems.' Although in some cases they respond to antibiotics, surgery is often necessary but is associated with a high incidence of postoperative infection, recurrence, and mamillary fistulas. The aetiology of periareolar inflammation is often unclear, though it occurs in association with periductal mastitis and duct ectasia. We report a case of recurrent bilateral periareolar abscesses.

\section{Case report}

A 21 year old woman who had been a women's hairdresser for some years and had recently begun to cut men's hair presented with a three month history of periareolar inflammation that was resistant to treatment with antibiotics. She had a palpable mass at the edge of her areola and a partially inverted nipple. Biopsy showed periductal mastitis. Soon afterwards she presented with periareolar inflammation in her other breast with intermittent purulent discharge. When indicated clinically an abscess was drained and the cavity packed. No organisms were cultured from the drained material. Over the next three months she had frequent abscesses on both breasts requiring surgical drainage.

At this stage she gave a history of having to remove short hairs protruding from her nipples at the end of a working day. When the next abscess formed a search for hair produced nothing, but a clump of short hairs was found in the cavity of the subsequent abscess. With the next recurrence digital pressure from within the cavity of the abscess extruded hair through the mammary ducts (figure). By this technique hair was cleared from the ducts and recurrence of abscesses stopped. Histological examination of the wall of the cavity showed birefringent foreign material that was identified as hair. 